\title{
REVITALISASI POTENSI SAUJANA BUDAYA KAWASAN PERDESAAN KREBET YOGYAKARTA BERBASIS PADA AKTIVITAS EKO-EKONOMI
}

\author{
Amiluhur Soeroso ${ }^{1}$ \\ STIE API Pariwisata \\ Y. Sri Susilo ${ }^{2}$ \\ Universitas Atma Jaya Yogyakarta
}

\begin{abstract}
This research aims to profile precisely strategy for the cultural landscape revitalization of Krebet region with an eco-economy approach. Data were obtained from 200 person of community which doing acitivity in Krebet with structured questionnaire; and conducted by using both factor and cluster analysis. After that, as a result of Delphi method, the policy was shaped by exploring 15 experts. The priorities of policy are confirmed by analytic hierarchy process (AHP).

The results indicate that revitalization indicators of Krebet's cultural landscape are: (1) ecomuseum (conservation of panoramic landscape and traditionally agriculture) and conservation of forestry function (biodiversity management and planting various trees); (2) eco-culture (uses local resources, living culture conservation and handicraft innovation) and cultural heritage conservation (tradional arts and cultural heritage). All utilizing of the attributes based on ecoeconomy that respects an environmentally sustainable economy. It requires that the principles of ecology establish the framework for the formulation of economic policy and that economists and egologist work together to fashion the new economy. Hence, an eco-economy is perhaps a new paradigm to an immediate needed change.

For the reason, the survival of Krebet's site in the future will fully depend on its sustainable development policy to those attributes. Management of cultural landscape in Krebet should have to focus on natural and cultural - a cultural landscape - resources where human being living.
\end{abstract}

Keywords: Krebet, cultural landscape, eco-economy, revitalization

\section{PENDAHULUAN}

Kawasan perdesaan Krebet terletak di Kabupaten Bantul, lima belas kilometer sebelah barat-daya kota Yogyakarta. Daerah ini berimpit dengan Desa Kasongan yang terkenal akan produkgerabahnya. Krebetmenawarkan daya tarik kebudayaan yang berpadu dengan alam dalam bentuk saujana budaya (cultural landscape) seperti kerajinan batik kayu, bentang alam perbukitan Karst yang menawarkan keindahan panorama sekaligus sebagai lahan jelajah wisata (trekking), aliran Sungai Progo yang dapat dimanfaatkan untuk arung jeram dan sebagainya. Banyak wisatawan yang telah berkunjung ke daerah ini. Namun karena belum optimalnya pemanfaatan potensi sumberdaya yang dimilikinya menjadikan kehidupan masyarakat kawasan ini belum sejahtera, tertinggal dari daerah lainnya. Alam yang menjadi tumpuan hidup dieksploitasi denga tidak semena-mena (misalnya penambangan bukit kapur yang menyebabkan erosi dan berkurangnya hasil lahan pertanian) mengganggu keseimbangan ekosistem di daerah tersebut, sedangkan kearifan kebudayaan lokal masyarakat (misalnya penggiliran dua masa tanam padi dengan sisipan palawija yang dapat mengikat $\mathrm{N}_{2}$ sehingga tanah menjadi gembur) mulai ditinggalkan.

Padahal bila kekayaan daerah ini dapat dikelola dengan baik maka akan menjadikan prima donna yang

1 Pengajar pada STIE Pariwisata API dan Dosen luar biasa pada Universitas Atma Jaya dan Universitas Gadjah Mada Yogyakarta. Alamat e-mail: amisoeroso@gmail.com

2 Dosen Universitas Atma Jaya Yogyakarta. Alamat e-mail: yss@fe.uajy.ac.id 
memberikan kontribusi peningkatan kualitas hidup masyarakat terutama bagi daerah yang tidak memiliki kawasan industri atau pertanian yang besar. Tetapi keuntungan jangka pendek dan kepentingan kelompok seringkali menjadi prioritas sehingga menyebabkan degradasi dan pemusnahan lingkungan (ecocide). Padahal jika dapat diatasi, publik akan mendapat pengalaman kebudayaan yang integral sehingga perilaku antropogenik manusia sangat menentukan kelangsungan lingkungan hidup bagi kepentingan generasi sekarang dan mendatang. Oleh sebab itu sumberdaya yang ada harus dipergunakan secara efektif dan efisien bukan dieksploitasi secara maksimal.

Untuk itu perlu sebuah upaya revitalisasi untuk menghidupkan potensi saujana budaya di Krebet yang berbasis pada kearifan lokal. Sasarannya adalah pembangunan, tidak dalam koridor pertumbuhan perekonomian saja tetapi holistik. Oleh karena itu permasalahan yang muncul adalah apakah faktor-faktor yang dapat dijadikan indikator revitalisasi Kawasan Krebet? Penelitian ini bertujuan untuk menampilkan strategi pembangunan kawasan perdesaan Krebet dengan tepat.

\section{TINJAUAN PUSTAKA}

Pembangunan ekonomi pada dasarnya tidaklah dapat berdiri sendiri tanpa memperhatikan variabel lain yang menjadi tumpuan semua makhluk hidup, yaitu sistem ekologi atau lebih dikenal sebagai ekosistem. Selain itu di dalam pembangunan berkelanjutan yang notabene merupakan pembangunan holistik di segala bidang, area bentanglahan (landscape) selama ini jarang sekali menjadi fokus perhatian. Padahal di sini, bentanglahan mencakup pengertian lingkungan fisik secara integral termasuk iklim, topografi, tata air (hidrologi) bahkan hingga keadaan vegetasi alami yang semuanya seara potensial mempengaruhi penggunaan lahan termasuk kebudayaan masyarakat yang mendiaminya. Unsur bentanglahan mewakili kepentingan alam dan merupakan kunci dari lingkungan, komunitas vegetasi dan hewan termasuk manusia.

Untuk itu, perlulah dipahami rangkaian atau hubungan antara ekosistem dan pelestarian bentanglahan dalam bentuk ekomuseum, peranan eko-budaya dan pada akhirnya berujung pada aktivitas eko-ekonomi. Seluruh kegiatan tersebut termaktub pada sebuah saujana budaya (cultural landscape) yang dimiliki oleh sebuah wilayah.

\subsection{Ekosistem}

Ekosistem, tatanan unsur lingkungan hidup yang merupakan kesatuan utuh menyeluruh, saling mempengaruhi dalam membentuk keseimbangan, stabilitas, dan poduktivitas lingkungan hidup (Pasal 1 butir 4 UUPLH Nomor 23 tahun 1997). Bentuk jasanya bernilai ektrinsik dan intrinsik (preservasi, pemeliharaan barang bagi kepentingan generasi mendatang), opsi (keanekaragaman), kebudayaan (estetika, artistik, pendidikan, spritual, keilmiahan) (Costanza, 1997: 388; Moons, 2003: 3).

Di dalam suatu ekosistem terkandung berbagai unsur baik alam, kebudayaan manusia maupun gabungan keduanya. Ketiganya merupakan sumberdaya penting, yang perlu dilestarikan, sehingga menjadi bagian kemitraan yang mutual benefit dengan industri pariwisata (Wight, 1993: 5). Oleh karena itu, agar lingkungan dapat dinikmati, digunakan dan tidak dihancurkan diperlukan upaya: (1) preservasi yaitu pencegahan degradasi lingkungan dan menjaga kelestariannya agar tetap pada kondisi yang ada; dan (2) konservasi yaitu perlindungan terhadap lingkungan yang dianggap mempunyai nilai penting baik historis, arsitektural, budaya dan lain-lain.

\subsection{Ekomuseum}

Ekowisata secara luas pengertiannya selain melakukan pelestarian, juga merespon ekologi, sosial-ekonomibudaya dan sejarah alam daerah (Merric dan Hunt, 1998: 37; Sirakaya dan McLellan, 1998: 42-43). Pariwisata ramah lingkungan atau ekowisata bukan hanya bentuk perjalanan ke alam saja, namun diinterpretasikan lebih luas meliputi konservasi budaya (Ayala, 1996: 46). Pengelolaan ekowisata yang sukses selain memberikan nilai tambah pada masyarakat, melindungi sumberdaya lahan, juga melestarikan nilai kebudayaan dan sosial, termasuk tempat bersejarah. 


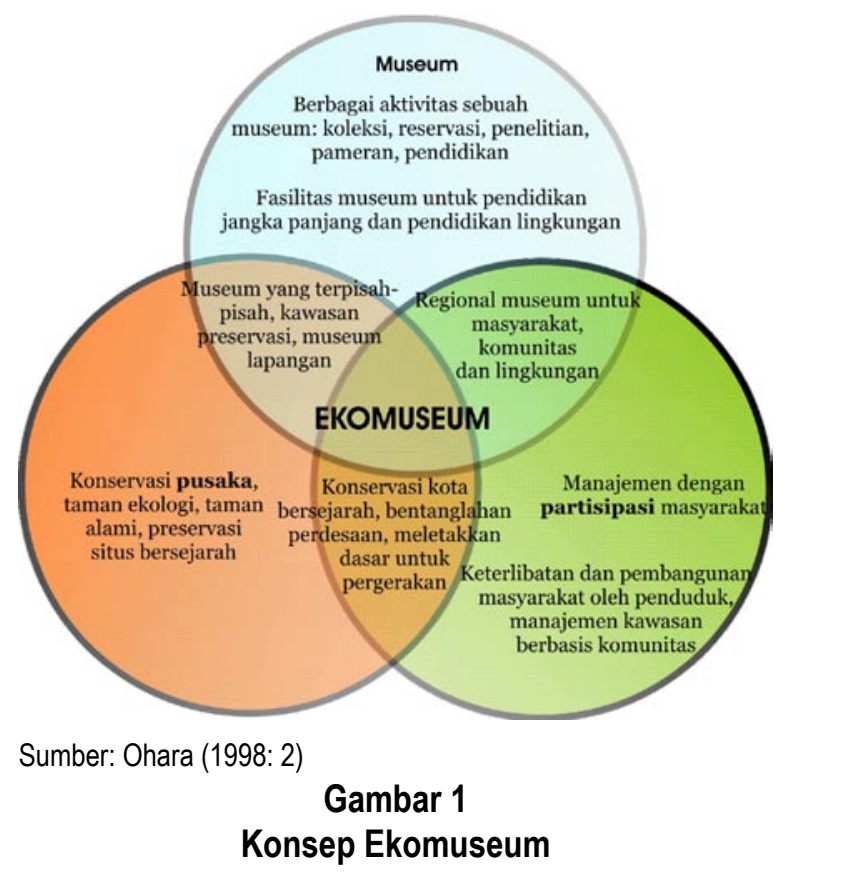

Perluasan definisi ekowisata tersebut melahirkan konsep ekomuseum yaitu aktivitas yang bersifat ekologi dengan tujuan mengembangkan suatu daerah sebagai sebuah living museum (Ohara, 1998: 1-3). Konsepnya adalah keseimbangan dan terintegrasinya tiga elemen yaitu pelestarian pusaka (heritage), partisipasi masyarakat dan aktivitas sebuah museum (Gambar 1).

\subsection{Eko-Ekonomi}

Konsep pembangunan berkelanjutan telah muncul seperempat abad yang lalu, namun tidak satu negara pun memiliki strategi untuk membangun ekonomi dengan menjaga keseimbangan karbon, menstabilisasikan populasi dan sekaligus melestarikan hutan, tanah dan keanekaragaman hayati flora dan fauna. Hanya beberapa negara yang sukses melakukan satu atau dua elemen tersebut tetapi tidak ada yang dapat melakukan keseluruhan dengan memuaskan. Mengembalikan keseimbangan alam merupakan sebuah pekerjaan besar. Mengurangi erosi tanah sampai dengan tingkat formasi baru akan membutuhkan perubahan dalam agrikultur sehingga merupakan sesuatu yang tidak mudah.

Dengan demikian membangun perekonomian yang memperhatikan ekologi, atau disebut sebagai ekoekonomi, dengan tujuan memuaskan kebutuhan saat ini tanpa membahayakan kebutuhan generasi di masa depan (Brown, 2001: 77-78) merupakan sesuatu yang tidak mudah. Perekonomian dapat berkelanjutan hanya jika memperhatikan prinsip-prinsip ekologi; bila tidak, akan menyebabkan penurunan dan secepatnya runtuh. Oleh karena itu, perbaikan perilaku buruk pengelolaan ekologi termasuk dampak lingkungan dan eksternalitasnya perlu menjadi perhatian. Terutama pada eksistensi pengetahuan tradisional dan penggunaan bahan baku lokal.

\subsection{Saujana Budaya}

Saujana budaya, yang memiliki konotasi sejauh mata memandang, adalah gabungan dari elemen bentukan alam atau kebudayaan hasil cipta, rasa, karsa dan karya manusia yang istimewa dalam kesatuan ruang dan waktu (JPPI, 2003). Modal kebudayaan merupakan penghasil nilai ekonomi dan budaya dengan memasukkan unsur nilai yang dimiliki masyarakat seperti sosial, sejarah dan dimensi kebudayaan lainnya (Throsby, 1999: 12, 2001: 23; Benhamou dalam EUR, 2003: 255, Klamer dan Zuidhof dalam GCI, 1998: 23-24). Menurut Throsby (ANU, 2000: 12), konsep sumberdaya kebudayaan memiliki beberapa persamaan dengan sumberdaya alam dalam hal sifat 
pembangunannya yang ecological economics.

The World Heritage Committee (WHC), dan Australia ICOMOS (1995) menyatakan bahwa saujana budaya teraplikasikan pada suatu kawasan bentanglahan (landscape) yang memiliki penampakan alam dengan arti khusus bagi manusia untuk dikembangkan. Terminologi saujana budaya merupakan manifestasi keanekaragaman interaksi antara manusia dan lingkungan alamnya. Saujana budaya merepresentasikan sebuah kontinum pola penggunaan lahan yang melampaui beberapa generasi. Bentanglahan ini merupakan ekspresi evolusi dari nilai-nilai kebudayaan manusia, norma-norma dan sikap terhadap lahan tersebut. Sikap ini terungkap melalui kualitas visual dari sisa sejarah pengaruh manusia pada bentanglahan modern. Jadi, saujana budaya dibuat melalui hubungan yang intensif antara kebudayaan dan alam yang membentuk lingkungan dalam waktu yang lama dan menghasilkan bentanglahan di masa kini. Oleh karena itu kebudayaan dan bentanglahan berhubungan sangat kuat. Kebudayaan lahir dari bentanglahan seperti pembentukan keyakinan dan nilai manusia terhadap sumberdaya yang mengelilingi dan merangkainya (Coleman, 2002).

\subsection{Pariwisata Budaya}

Kebudayaan merupakan salah satu faktor yang menentukan keatraktifan sebuah daerah tujuan wisata. Elemen kebudayaan sebuah masyarakat adalah sebuah kompleks yang merefleksikan cara mereka hidup, bekerja dan berkarya. Pariwisata budaya meliputi seluruh aspek perjalanan ditempat orang belajar tentang setiap cara hidup dan pemikiran orang lain. Dengan demikian pariwisata merupakan sarana promosi penting dalam hubungan kebudayaan dan kerjasama internasional. Sebaliknya, pembangunan faktor-faktor kebudayaan merupakan sarana untuk meningkatkan sumberdaya untuk menarik wisatawan. Di banyak negara, pariwisata dapat diasosiasikan dengan kebijakan "hubungan kebudayaan". Hal ini digunakan untuk mempromosikan bukan hanya pengetahuan dan pengertian tetapi juga sebuah citra yang menarik dari sebuah bangsa di antara bangsa lain di pasar pariwisata (Goeldner dan Ritchie, 2003).

Smith (1977) menyatakan pariwisata etnik menekankan pada tujuan mengobservasi ekspresi kebudayaan dan gaya hidup dari sebuah masyarakat yang benar-benar eksotik. Pariwisata ini meliputi kunjungan ke rumah tradisional, menghadiri pementasan tari dan upacara tradisional serta berpartisipasi pada ritual keagamaan. Kemudian juga makan di hotel di daerah perdesaan, melihat cara bertani, pembuatan kerajinan, sistem pendidikan (misalnya berlatih ketrampilan membuat kerajinan - menganyam, menenun dan lain-lain) dan sebagainya.

Salurannya melalui elemen kebudayaan seperti keramah-tamahan, rancangan arsitektur, kuliner, produk kerajinan tangan sebuah daerah dan seluruh karakteristik cara hidup (way of life) masyarakatnya. Namun demikian, atraksi kebudayaan harus ditampilkan dengan cara yang cerdas dan kreatif. Oleh karena itu di sini terlihat sebuah kebutuhan yang besar untuk meningkatkan keanekaragaman kebudayaan (cultural diversity). Selaras dengan itu, sumberdaya yang terhampar di Kawasan Krebet seperti keindahan alam, sosial budaya, sejarah, kesenian, kuliner, merupakan kekuatan untuk menarik pengunjung.

\section{METODE PENELITIAN}

\subsection{Daerah Penelitian}

Daerah penelitian meliputi Kawasan Krebet, yang terletak di seputar Desa Sendangsari, Kecamatan Pajangan, Kabupaten Bantul, Daerah Istimewa Yogyakarta. Letak daerah ini sepuluh kilometer di sebelah barat laut Kota Bantul (Gambar 2).

Dalam penelitian ini dusun-dusun di sekitar Kawasan Krebet yang diikutkan menjadi obyek penelitian adalah Pucung yang terkenal sebagai tempat pembuatan patung-patung dengan gaya primitif yang terbuat dari kayu mahoni dan jati. Desain patung-patung ini bersumber dari pola dan tema tradisional dari berbagai daerah seperti Asmat, Dayak dan lain-lain. Tema ini kemudian dikembangkan menjadi ornamen benda fungsional seperti meja sudut, tempat lilin, dan lain-lain, atau berdiri sendiri sebagai elemen estetika. Kemudian Dusun Gendeng, sentra kerajinan kulit khususnya ukir wayang kulit gaya Yogyakarta. 


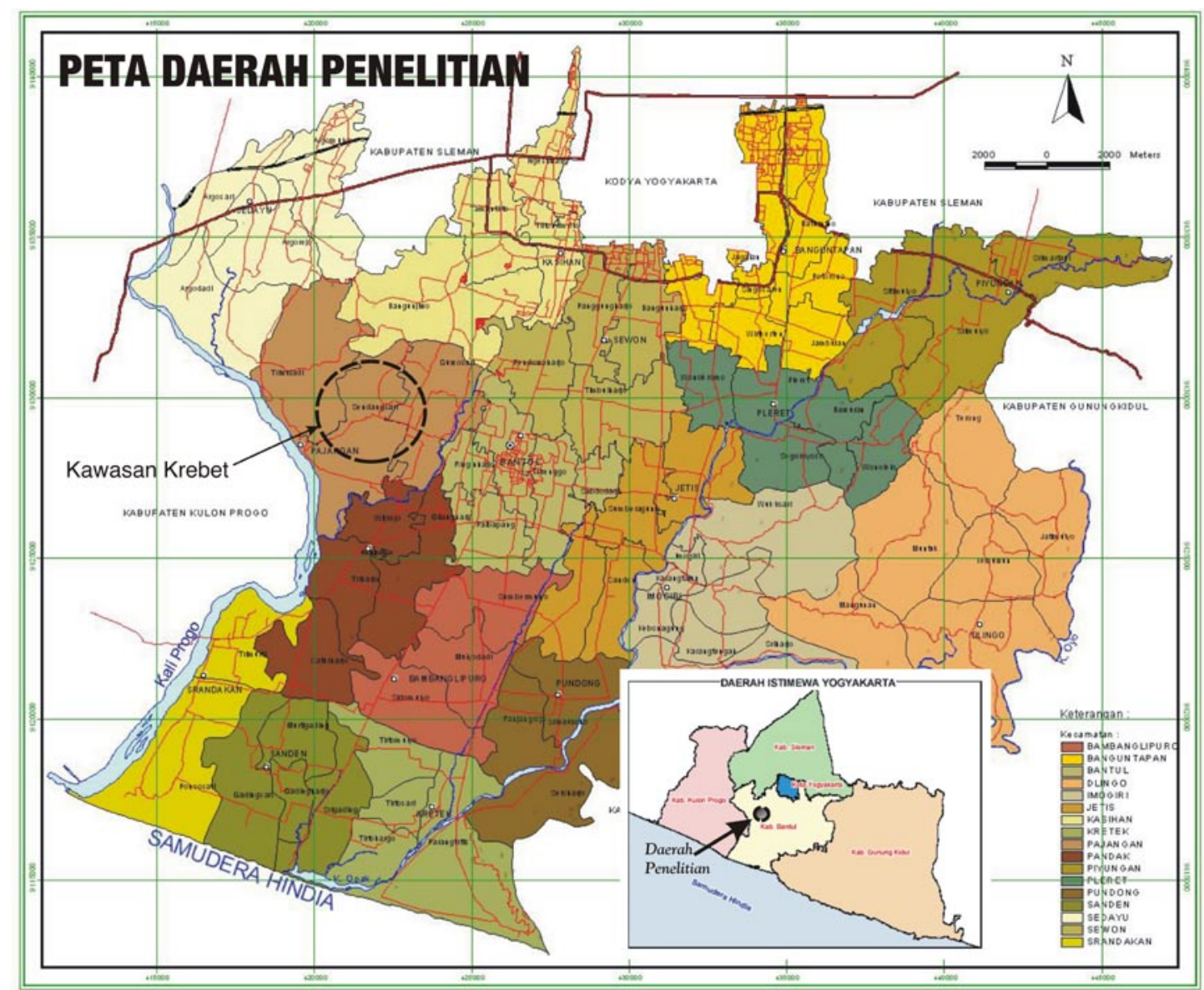

Sumber: Pengolahan Data (2007)

\section{Gambar 2 \\ Daerah Penelitian}

\subsection{Sampel}

Representasi sampel tergantung pada: (1) tingkat keyakinan yang diinginkan, (2) jumlah kesalahan yang dapat ditoleransi dan (3) jumlah penyebaran (dispersi) dalam populasi yang ditaksir (Palumbo, 1977: 279). Zikmund (1991: 510-511) berpendapat bahwa besarnya ukuran sampel dapat juga ditentukan menurut pertimbangan keilmuan (professional judgement) peneliti. Ada beberapa teknik menentukan ukuran sampel, salah satunya menurut Watson et al. (1993: 333-371) ukuran sampel ditentukan dengan formula sebagai berikut:

$$
\mathrm{n}=\frac{4 \cdot Z_{? \alpha}^{2} \mathrm{p}(1-\mathrm{p})}{(\omega)^{2}}
$$

$n$ merupakan ukuran sampel, $p$ adalah proporsi kesuksesan yang diharapkan dari sampel, $q$ adalah proporsi sisa (1-p), $Z_{1 / 2 \alpha}$ adalah koefisien konfidensi, $\omega=L+R$ adalah jumlah kesalahan yang dapat ditoleransi dari rerata populasi pada batas kiri (L) dan batas kanan (R). Berdasarkan pendapat Palumbo (1977: 279), Zikmund (1991: 510-511) dan Watson et al. (1993: 360) ditetapkan kriteria: (1) proporsi kesuksesan yang diharapkan dalam 
penelitian ini $(p)$ mencapai 99 persen atau tingkat kegagalannya $(q)$ sebesar 1\%; (2) error $(\alpha)$ ditetapkan sebesar $1 \%$ atau tingkat konfidensinya 99 persen sehingga dari tabel dapat diketahui $Z_{1 / 2 \alpha}=2,58$. Dengan menetapkan 200 orang responden maka diperoleh $\omega$, $L$ dan $R$ sebesar:

$200=\left\{4 \cdot(2,58)^{2} \cdot(0,99) \cdot(0,01)\right\} / \omega^{2}=0,2636 / \omega^{2} ;$ atau $\omega=0.0363 \approx 3,6 \%$, sehingga $L=R=1,8 \%$. Data primer yang dikumpulkan dengan cara survei terhadap responden secara purposif terhadap berbagai elemen seperti tokoh masyarakat, guru, aktivis LSM, muspida dan anggota masyarakat lain yang melakukan kegiatan di kawasan Krebet.

\subsection{Instrumen Penelitian}

Untuk mengetahui pemahaman masyarakat terhadap kelestarian lingkungan hidup dilakukan survei dengan melakukan wawancara terhadap mereka. Pengukuran difokuskan berdasarkan tiga elemen pendukung kepariwisataan yaitu atraksi, aksesbilitas dan amenitas. Selanjutnya untuk menganalisis data empirik digunakan analisis faktor untuk menentukan faktor-faktor dari subyek yang diteliti dengan mereduksi jumlah keseluruhan dari pernyataan-pernyataan yang ada pada kuesioner. Inti setiap faktor dibentuk dari setiap pernyataan yang berhubungan dengan yang lain dan kelompok pernyataan yang membentuk faktor (Hair et al., 2006: 114-115; Santosa, 2000: 100-101). Skor faktor yang diperoleh dijadikan masukan untuk analisis cluster (kelompok). Kemudian, berlandaskan pada hasil analisis tersebut, kebijakan, strategi dan taktik operasional revitalisasi dikonfimasikan dengan 15 orang pakar. Sistem yang dilakukan adalah dua putaran pertemuan. Terakhir dilakukan proses hirarki analitik (Analytical Hierarchy Process, AHP) dengan menggunakan perangkat lunak expert choice untuk menentukan prioritasnya.

Namun demikian, agar tidak ambigu, maka sebelum dilaksanakan survei di lapangan, dilakukan dahulu uji terhadap instrumen penelitian. Uji terhadap kuesioner, dengan teknik $\alpha$-cronbach dilakukan untuk mengetahui validitas dan reliabilitasnya.

\section{HASIL PENELITIAN}

\subsection{Profil Responden}

Dari 200 orang responden yang diteliti, lima puluh sembilan persen merupakan wanita, kebanyakan berpendidikan sekolah lanjutan atas $(39 \%)$, bekerja pada sektor swasta $(53 \%)$, merupakan kaum muda berusia 26-36 tahun (41\%) yang memiliki jumlah tanggungan rerata dua orang dengan penghasilan sampai dengan Rp 1,5 juta per bulan $(36 \%)$.

Profil ini memperlihatkan bahwa berbagai elemen seperti tokoh masyarakat, guru, aktivis LSM, muspida dan anggota masyarakat lain yang dijadikan responden masih dalam usia produktif melakukan kegiatan di kawasan Krebet, sehingga dari pengalaman berinteraksi dengan masyarakat di daerah tersebut, mereka dapat memberikan kontribusi yang cukup signifikan dalam penelitian ini.

\subsection{Pengujian Instrumen Penelitian}

Pengujian alpha Cronbach dengan menggunakan 30 orang responden $(n)$ memperlihatkan bahwa seluruh butir kuesioner memiliki $r$ hitung bertanda positif dan lebih besar dari titik kritis $(r$ tabel $=0,361$ pada $\mathrm{df}=\mathrm{n}-2$, dan tingkat signifikan $5 \%$ ). Pada pengujian reliabilitas instrumen alam $(0,609)$, dan budaya $(0,741)$ memiliki skor positif lebih besar dari $r$ tabel. Dengan demikan instrumen tersebut dinyatakan valid dan reliabel sehingga dapat dipergunakan dalam penelitian.

\subsection{Indikator Revitalisasi Saujana Budaya}

\subsubsection{Potensi Alam}

Dengan menggunakan sampel 200 orang, maka titik kritis factor loading yang dibutuhkan untuk menginterpretasi analisis faktor adalah sebesar 0,40 (Hair et al., 2006: 128). Tiga faktor alam seperti terlihat pada Tabel 1 sebagai indikator penting revitalisasi Kawasan Krebet secara subyektif diberi nama:(1) pelestarian panorama 
alam yang meliputi perlunya pemeliharaan bahan alam, pengelolaan lahan kapur yang benar, pelestarian daerah di sekitar perbukitan, penghijauan perbukitan, perlunya dukungan masyarakat, penggunaan produk ramah lingkungan; (2) pemanfaatan lahan dengan pertanian ladang yang diolah dengan cara tradisional - penggunaan pupuk organik dengan memanfaatkan lahan tadah hujan; dan (3) pelestarian fungsi hutan dengan menjaga keanekaragaman hayati serta pelestarian pohon jati dengan melakukan penebangan secara tepat sehingga menghasilkan kayu bernilai ekonomis.

Panorama alam yang indah perlu dilindungi karena merupakan aspek penting serta menjadi daya tarik dan impian orang yang ingin mendapatkan ketenangan jiwa, penambangan bahan gamping menimbulkan eksternalitas negatif berupa degradasi lingkungan. Ongkos yang ditanggung masyarakat dari erosi tanah, infeksi saluran pernafasan bagian atas (ISPA) akibat $\mathrm{PM}_{10}$, debu yang menutupi vegetasi pada lahan pertanian sehingga menurunkan produktivitasnya dan lain-lain, tidak sebanding dengan penerimaan pemerintah dari retribusi yang diterima dari usaha ini. Kemudian pemupukan dengan menggunakan pupuk organik akan menyebabkan tanah tidak menjadi asam sehingga tidak rusak, selain itu pada waktu musim kemarau lahan dapat ditanami tanaman yang tidak butuh air banyak tetapi dapat mengikat Nitrogen $\left(\mathrm{N}_{2}\right)$ yang berfungsi sebagai penggembur tanah. Upaya pemupukan alami ini sekaligus dijadikan persiapan bagi penanaman tanaman pangan di musim penghujan.

Vegetasi yang hidup di hutan di sekitar Krebet seperti alang-alang (Imperata clindrica) dapat dimanfaatkan sebagai obat muntah, Kelor (Motinga oleifera) untuk obat rematik dan oedim, Mindi (Melia azedercaei) untuk obat cacingan, Mahoni (Swietenia mahagoni) untuk obat eksim, deman dan hipertensi. Sementara fauna yang eksis adalah Ayam hutan (Gallus varius), Tupai (Tupaia sp.), Gemak tegalan (Tumix silvalica), Perkutut (Geopelia strata), Luwak (Paradoxurus hermaphoditus) serta Kelelawar (Ostechthyes) yang membantu pemberantasan hama secara alami dan menjaga kelangsungan hidup tumbuhan tertentu melalui penyerbukan dan penyebaran biji dan juga ular Sawa (Phyton Sp.) yang mengendalikan hama tikus.

Tabel 1

Indikator Potensi Alam

\begin{tabular}{|c|c|c|c|c|}
\hline Item & 1 & 2 & 3 & Keterangan \\
\hline A03: pelestarian panorama alam & 0.850 & 0.170 & 0.050 & Pelestarian panorama alam \\
\hline A05: pemeliharaan bahan alam & 0.690 & 0.150 & 0.220 & \\
\hline A04: pengelolaan lahan batu kapur & 0.630 & 0.360 & 0.360 & \\
\hline A11: pelestarian daerah penyangga & 0.590 & 0.430 & 0.320 & \\
\hline A02: upaya penghijauan & 0.550 & 0.380 & 0.050 & \\
\hline A06: dukungan masyarakat & 0.520 & 0.320 & 0.000 & \\
\hline A13: produk ramah lingkungan & 0.500 & 0.280 & 0.400 & \\
\hline A01: perlindungan perbukitan kapur & 0.480 & 0.270 & 0.130 & \\
\hline A08: pertanian ladang tradisional & 0.160 & 0.840 & 0.380 & Pertanian ladang tradisional \\
\hline A07: bercocok tanam tradisional & 0.480 & 0.680 & 0.110 & \\
\hline A10: pemanfaatan lahan kering & 0.370 & 0.490 & 0.240 & \\
\hline A09: ketergantungan terhadap ladang & 0.280 & 0.480 & 0.000 & \\
\hline A15: pelestarian fungsi hutan & 0.130 & -0.010 & 0.870 & Pelestarian fungsi hutan \\
\hline A14: pengelolaan keanekaragaman & 0.040 & 0.170 & 0.620 & \\
\hline A12: pelestarian hutan jati & 0.520 & 0.350 & 0.570 & \\
\hline Eigenvalues & 6.922 & 1.599 & 1.221 & \\
\hline
\end{tabular}


Kekayaan fauna lain yang selama ini kurang dikenal adalah kupu-kupu besar atau ngengat spesies Attacus atlas dan Cricula trifenestrata. Keduanya merupakan produsen benang sutera liar (wildsilk); sifatnya bukan budidaya manusia di dalam kandang, namun hidup di alam liar. Kedua spesies ini banyak ditemukan di kebunkebun penduduk atau di sepanjang igir bukit, biasanya di pohon kedondong, jambu mete, rambutan, alpukat dan sebagainya. Mereka menimbulkan kerusakan dahsyat karena daun pohon inangnya gundul. Oleh karena itu ulat tersebut, oleh masyarakat yang belum mengetahui potensinya, dianggap musuh dan dibasmi padahal semestinya dapat memberikan nilai tambah ekonomi. Ciri khas benang sutera yang dihasilkan menampakkan warna keemasan alami sehingga tidak perlu pewarnaan lagi. Produk sutera dengan benang yang berasal dari kedua kupu-kupu ini sangat mahal di pasar internasional, terutama Jepang dan Eropa.

Vegetasi dan fauna menjadi unsur lain dari alam yang membentuk saujana budaya kawasan Krebet. Menurut Almo Farina (Von Droste et al., 1995: 61-62, 72) heterogenitas adalah karakter penting dari saujana budaya; komponen bentanglahan (landscape) seperti bentuk dan ukurannya dapat mempengaruhi distribusi, kemelimpahan dan perilaku, pergerakan serta preferensi binatang. Mereka adalah organisme rentan yang membutuhkan area luas untuk hidup dan berkembang biak sehingga gangguan terhadap bentanglahan akan mengancam kehidupannya dan pada akhirnya akan mempengaruhi manusia itu sendiri. Flora dan fauna di Krebet menunjukkan interaksi antara kenekaragaman hayati (biological diversity) dan keanekaragaman budaya (cultural diversity) yang menjadi ukuran variasi kehidupan manusia sehingga merefleksikan hubungan antara manusia dan lingkungan alamnya. Alam, dalam konteks ini, adalah rekan pendamping bagi manusia; keduanya adalah kekuatan dinamis dalam membentuk saujana budaya (Von Droste et al., 1995: 15, 27).

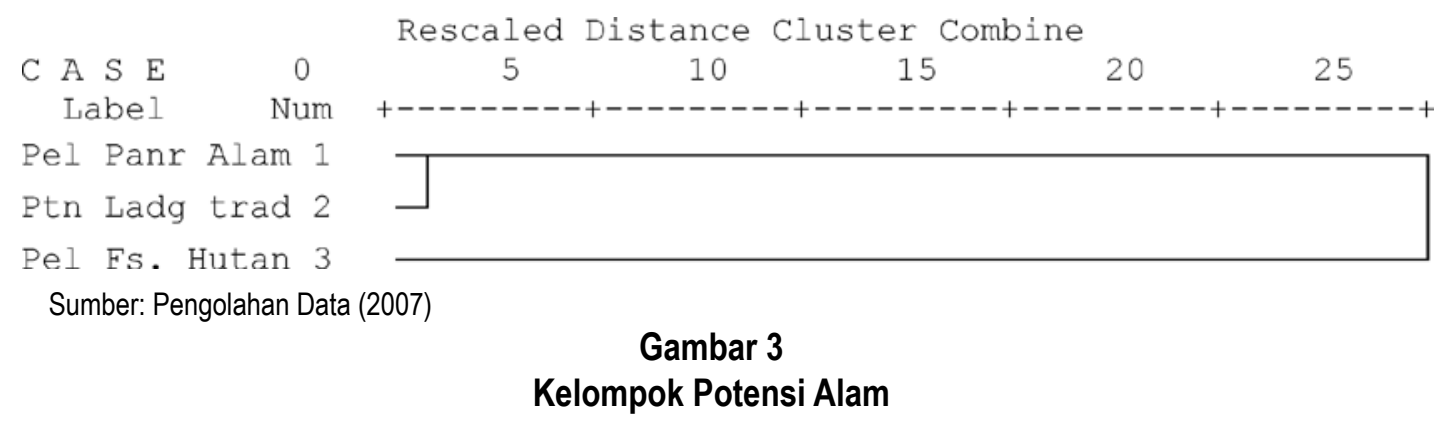

Kemudian, berdasarkan analisis cluster tiga faktor potensi alam bergabung menjadi dua kelompok yaitu: (1) pelestarian panorama alam dan pertanian ladang tradisional menjadi ekomuseum sedangkan (2) pelestarian fungsi hutan mandiri (Gambar 3).

\subsubsection{Potensi Kebudayaan}

Faktor potensi kebudayaan (Tabel 2) yang diharapkan dapat menunjang aktivitas pariwisata adalah (1) pelestarian sumberdaya lokal, (2) mempertahankan living culture; (3) menciptakan inovasi dalam menciptakan produk kerajinan dan (4) pelestarian warisan budaya. Pelestarian sumberdaya lokal harus mendapat dukungan dan partisipasi dari masyarakat. Bentuk khas rumah tradisional menjadi identitas masyarakat sehingga arsitektur bangunan vernakular (seperti atap rumah berbentuk joglo, limasan atau kampung dan sebagainya) perlu dipelihara. Kemudian perlu menumbuhkan kembali kepedulian generasi muda terhadap upacara adat dan ritual tradisional seperti merti bumi (sedekah kepada alam), besih desa sebagai bagian kebudayaan yang menjadi daya tarik wisata. Pemahamannya dapat dilakukan melalui pendidikan formal di sekolah dan informal melalui media arisan, paguyuban seni dan sebagainya.

Living culture (Gambar 4) berupa kehidupan keseharian masyarakat perdesaan lengkap dengan bahasa, tradisi oral dan cerita rakyatnya merupakan sumberdaya tidak berujud yang elok untuk dipertahankan, patung batik kayu yang menjadi ciri khas Krebet perlu ditonjolkan, juga sifat gotong-royong kerja sama memikul beban 
kehidupan dan kesadaran menggunakan kearifan lokal. Gotong-royong merupakan ciri khas budaya masyarakat yang ada sejak zaman baheula. Kebudayaan tersebut perlu dipertahankan karena membuat masyarakat kohesif dan kondusif, merasa senasib sepenanggungan, menumbuhkan ikatan emosional dan perasaan primordial, dan membuat solid hubungan di dalamnya sehingga tidak mudah untuk terfragmentasi atau terabrasi oleh kekuatan lain yang negatif. Faktor keramah-tamahan merupakan unsur lain yang menunjang aktivitas pariwisata budaya yang dapat dikembangkan di sana. Dari segi sosial-budaya, di dalam masyarakat tumbuh paguyuban sosial seperti arisan, pengajian, asosiasi pedagang dan sebagainya. Di samping itu, kegiatan rembug desa yang biasa digunakan sebagai media dalam memutuskan suatu persoalan atau kebijakan yang akan diambil masyarakat perlu dipertahankan.

Tabel 2

Indikator Potensi Kebudayaan

\begin{tabular}{lllllll}
\hline \multicolumn{1}{c}{ Item } & $\mathbf{1}$ & $\mathbf{2}$ & $\mathbf{3}$ & $\mathbf{4}$ & Keterangan \\
\hline B03: pelestarian sumberdaya lokal & $\mathbf{0 . 8 3}$ & 0.51 & 0.22 & -0.03 & Pelestarian sumberdaya lokal \\
B05: pelestarian properti lokal & $\mathbf{0 . 7 4}$ & 0.22 & 0.31 & 0.16 & \\
B02: ketertarikan terhadap upacara adat & $\mathbf{0 . 6 7}$ & 0.27 & -0.05 & 0.50 & \\
B06: pelestarian ritual kebudayaan lokal & $\mathbf{0 . 6 6}$ & 0.16 & 0.12 & 0.29 & \\
B04: pemahaman kesenian lokal & $\mathbf{0 . 5 6}$ & 0.43 & 0.51 & 0.13 & \\
B01: acara upacara tradisional & 0.30 & 0.06 & 0.23 & 0.12 & \\
& & & & & \\
B14: mempertahankan living culture & 0.13 & $\mathbf{0 . 7 1}$ & 0.27 & 0.26 & Kehidupan masyarakat lokal \\
B13: kerajinan patung batik kayu & 0.34 & $\mathbf{0 . 6 3}$ & 0.24 & 0.01 & \\
B09: gotong-royong dan keraman-tamahan & 0.16 & $\mathbf{0 . 5 6}$ & 0.10 & 0.36 & \\
& & & & & \\
B11: inovasi kerajinan & 0.42 & 0.25 & $\mathbf{0 . 7 9}$ & 0.24 & Inovasi \\
B12: penggunaan transportasi tradisional & 0.35 & 0.42 & $\mathbf{0 . 6 7}$ & 0.19 & \\
B10: pelestarian paguyuban seni budaya & 0.00 & 0.39 & $\mathbf{0 . 5 9}$ & 0.42 & \\
B15: orientasi industri ke luar negeri & 0.13 & 0.54 & $\mathbf{0 . 5 6}$ & 0.06 & \\
& & & & & \\
B08: pelestarian kesenian tradisional & 0.25 & 0.35 & 0.30 & $\mathbf{0 . 8 3}$ & Warisan budaya \\
B07: pusaka budaya (heritage) & 0.44 & 0.05 & 0.29 & $\mathbf{0 . 5 9}$ & \\
Eigenvalues & 7.81 & 1.52 & 1.18 & 1.11 & \\
\hline Sigan & & & & &
\end{tabular}

Sumber: Hasil Pengolahan Data (2007)

Cinderamata sebagai pengingat keberadaan daerah tujuan wisata harus unik. Inovasi dalam pembuatan barang kerajinan yang bersifat fashion dilakukan dengan banyak mengikuti workshop, pameran, eksibisi dan sebagainya. Namun di dalam merancang produk perlu diperhatikan penggunaan pengetahuan tradisional yang menggunakan bahan baku lokal dari bahan-bahan alam sisa hasil pertanian yang dikenal ramah lingkungan namun selama ini diabaikan seperti rumput, bambu, bunga, daun, ranting dan dahan pohon, dan juga serangga, kepompong yang relatif tersedia banyak di sekitar perdesaan kawasan Krebet. Tujuannya adalah menciptakan perekonomian yang memperhatikan ekologi untuk memuaskan kebutuhan pada saat ini tanpa mengurangi hak generasi yang akan datang. 


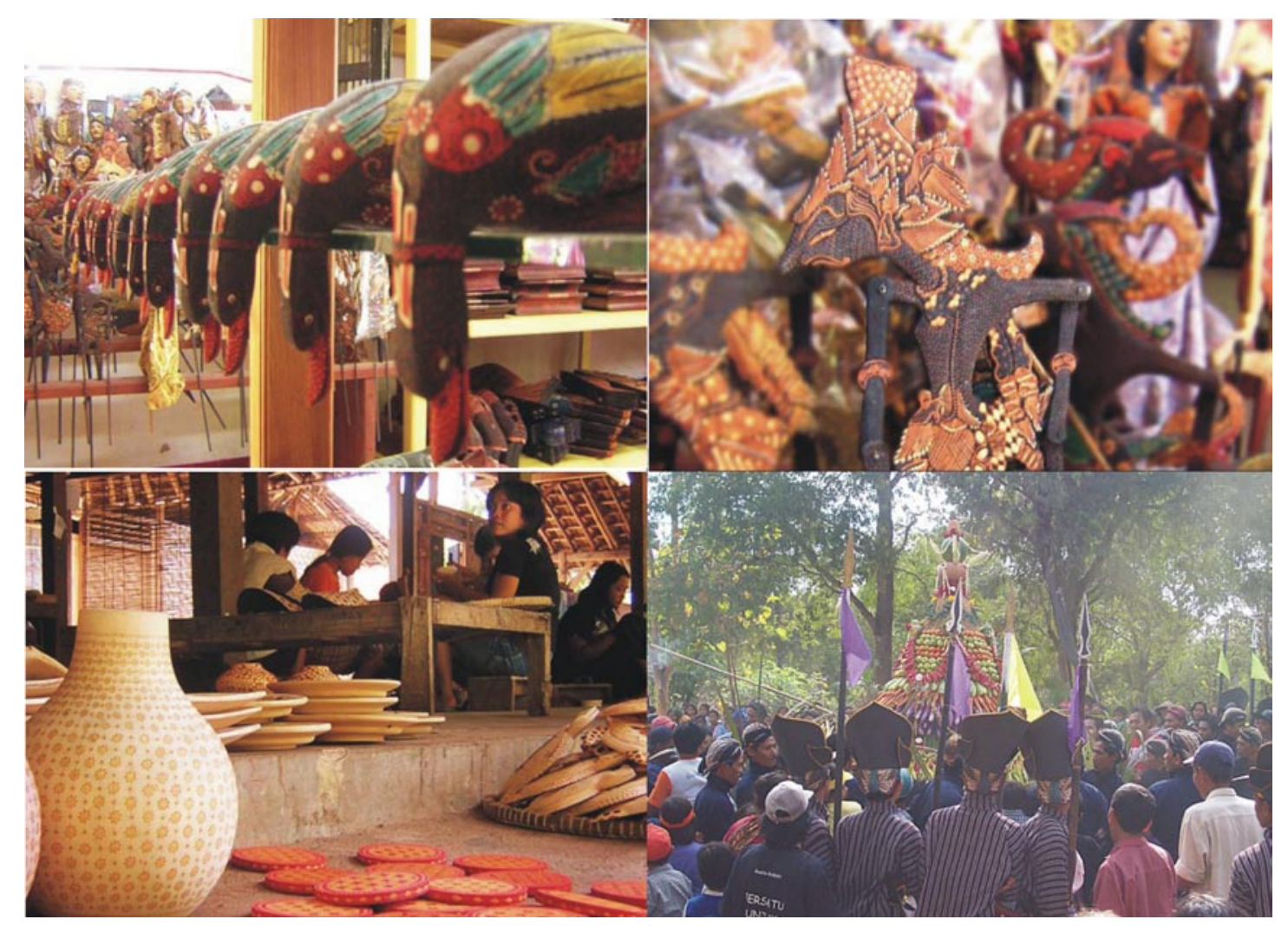

Sumber: Yogyayes.com (2007)

\section{Gambar 4}

Potensi Budaya Kawasan Krebet

Keterangan: Kerajinan Batik Ukir Kayu dan proses pembuatannya serta suasana Merti Bumi

Kegiatan ini dapat dikoordinasikan dengan Dewan Kerajinan Nasonal (Dekranas) atau instansi perindustrian dan perdagangan setempat. Kecuali itu para pengusaha dan pengrajin harus outward looking, menyesuaikan dengan kebutuhan pasar internasional. Perlu ditumbuhkan pula pasar kerajinan yang fungsinya selain tempat atraktif menggelar barang dagangan juga dikombinasikan dengan tempat menggelar acara kesenian yang dilaksanakan pada hari-hari tertentu yang dianggap penting, seperti hari kemerdekaan RI, untuk mengundang wisatawan datang mengunjunginya. Kemudian sarana transportasi tradisional seperti dokar, sepeda atau pedati yang telah digunakan selama beberapa generasi didorong untuk difungsikan kembali, kecuali ramah lingkungan dapat menjadi properti budaya yang dapat dikagumi oleh masyarakat lain. Dalam dunia pertukaran kebudayaan, properti lokal sangat digemari konsumen.

Di dalam hal warisan budaya sebaiknya diperlakukan sebagai monumen hidup dengan menggali atraksi dari peninggalan nenek moyang baik yang berujud (tangible heritage) maupun yang tidak berujud (intangible heritage). Pelestarian kesenian tradisional rakyat fokus pada pengembangan tampilan seni rupa (seni tata busana), seni kerajinan (batik dan patung) dan seni suara (seni vokal seperti nembang dan macapat termasuk karawitan dan juga seni tari) yang eksotis dan beranekaragam dengan ciri khas lokal. Pelestarian upacara adat perlu dikemas dengan nuansa atraksi yang memikat agar pengunjung merasa terlibat dan dapat menginterpretasikan keunikan atraksi kebudayaan yang ditampilkan. Pusaka budaya seperti rumah adat, masjid warisan leluhur dijaga agar tidak hilang. Klasifikasi dan warisan budaya yang ada di wilayah Krebet terpampang pada Tabel 3. 
Tabel 3

Klasifikasi Warisan Budaya

\begin{tabular}{ll}
\hline Klasifikasi & Warisan budaya berujud (Tangible heritage) \\
\hline Tidak Bergerak & $\begin{array}{l}\text { Warisan terbangun (built heritage) - monumen, bangunan, patung, inskripsi } \\
\text { (inscriptions), gua permukiman, bangunan tercatat: bangunan terpakai (buildings in } \\
\text { use), kelompok bangunan (group of buildings), pusat perkotaan }\end{array}$ \\
\hline & Situs (termasuk di bawah air) - arkeologi, sejarah, etnik \\
\hline Saujana budaya (cultural landscapes) \\
\hline Bergerak & Medifak - lukisan, patung, obyek, koleksi \\
\hline & Barang konsumen dan industri (consumer and industrial goods) \\
\hline & Warisan budaya tidak berujud (Intangible heritage) \\
\hline & Ekspresi seni (arts expressions) - musik, tari, literatur, teater \\
\hline & Seni bela diri (martial arts) \\
\hline & Bahasa \\
\hline & Kehidupan sehari-hari masyarakat (living cultures) \\
\hline & Tradisi oral (oral traditions) \\
& Cerita (narratives) \\
& Jaringan \\
\hline & Cerita rakyat (folklores) \\
\hline Revolusi \\
\hline
\end{tabular}

Untuk menunjang atraksi yang ditampilkan perlu pelestarian sumberdaya terutama karena banyaknya daerah yang memiliki sejarah alam dan sosial-budaya masyarakat yang penting yaitu melalui program ekomuseum. Program ini selain menekankan konservasi pada museum luar ruangan dengan melihat keterkaitan antara bentangalam perdesaan, ekologi, taman alam dan situs bersejarah juga di dalam manajemen pembangunannya melibatkan partrisipasi masyarakat. Hal lain yang perlu diperhatikan adalah pemberian pendidikan atau pemahaman terhadap konservasi lingkungan bagi pengguna karena orientasi hasilnya adalah jangka panjang. Fokus pemahaman yang diberikan adalah memperbaiki perilaku pengelolaan ekologi yang kurang baik, sehingga penting menonjolkan karakter ekobudaya yang memperhatikan secara holistik hubungan antara manusia dan lingkungan.

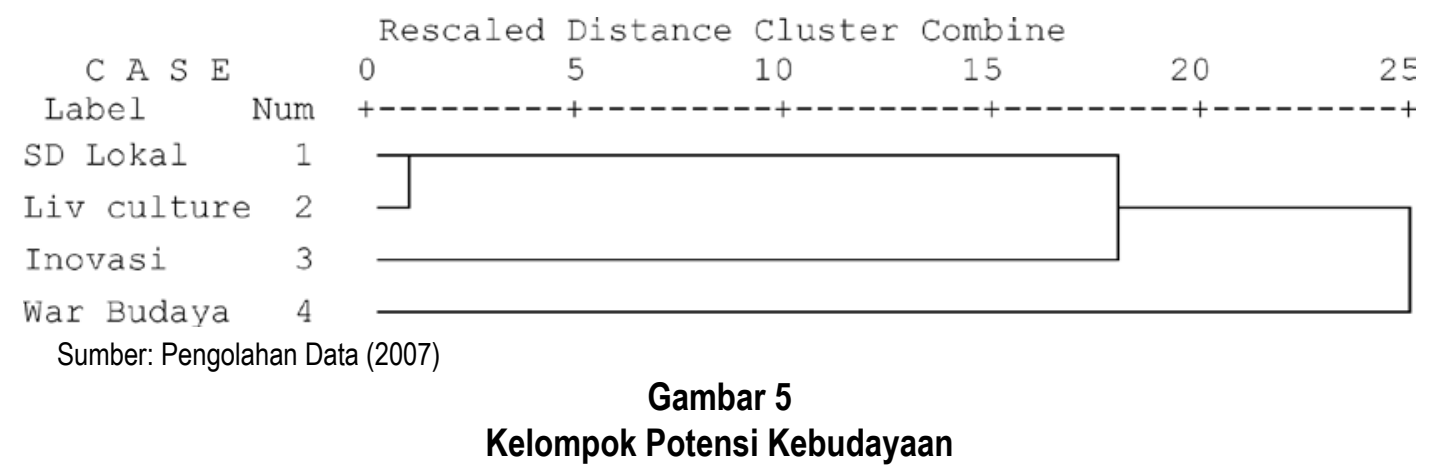

Analisis cluster (Gambar 5) memperlihatkan bahwa dua kelompok di dalam potensi kebudayaan yang eksis adalah: (1) bergabungnya pemakaian sumberdaya lokal, pelestarian living culture dan inovasi pada kerajinan dan cinderamata menjadi eko-budaya dan (2) warisan budaya berdiri sendiri. 


\subsubsection{Revitalisasi Saujana Budaya}

Hirarki kebijakan, strategi dan taktik digunakan dalam pengambilan keputusan terhadap upaya revitalisasi. Kebijakan mensintesiskan variasi prinsip-prinsip optimasi dengan kebijakan publik dan proses legal; atau keputusan yang didisain untuk deal dengan masalah sosial yang ada sehingga dapat diambil tindakan tertentu yang sesuai (Nagel, 1982: xiii). Adapun manajemen strategi dalam revitalisasi Kawasan Krebet dimaksudkan sebagai upaya untuk menyatukan antara rencana dan sumberdaya yang dimiliki (Langabeer II, 1998). Selanjutnya berdasarkan faktor dan kelompok indikator penting maka kebijakan, strategi dan taktik operasional yang perlu dilakukan dalam upaya revitalisasi Kawasan Krebet disusun pada Tabel 4.

Tabel 4

Kebijakan, Strategi dan Taktik Operasional Revitalisasi Krebet

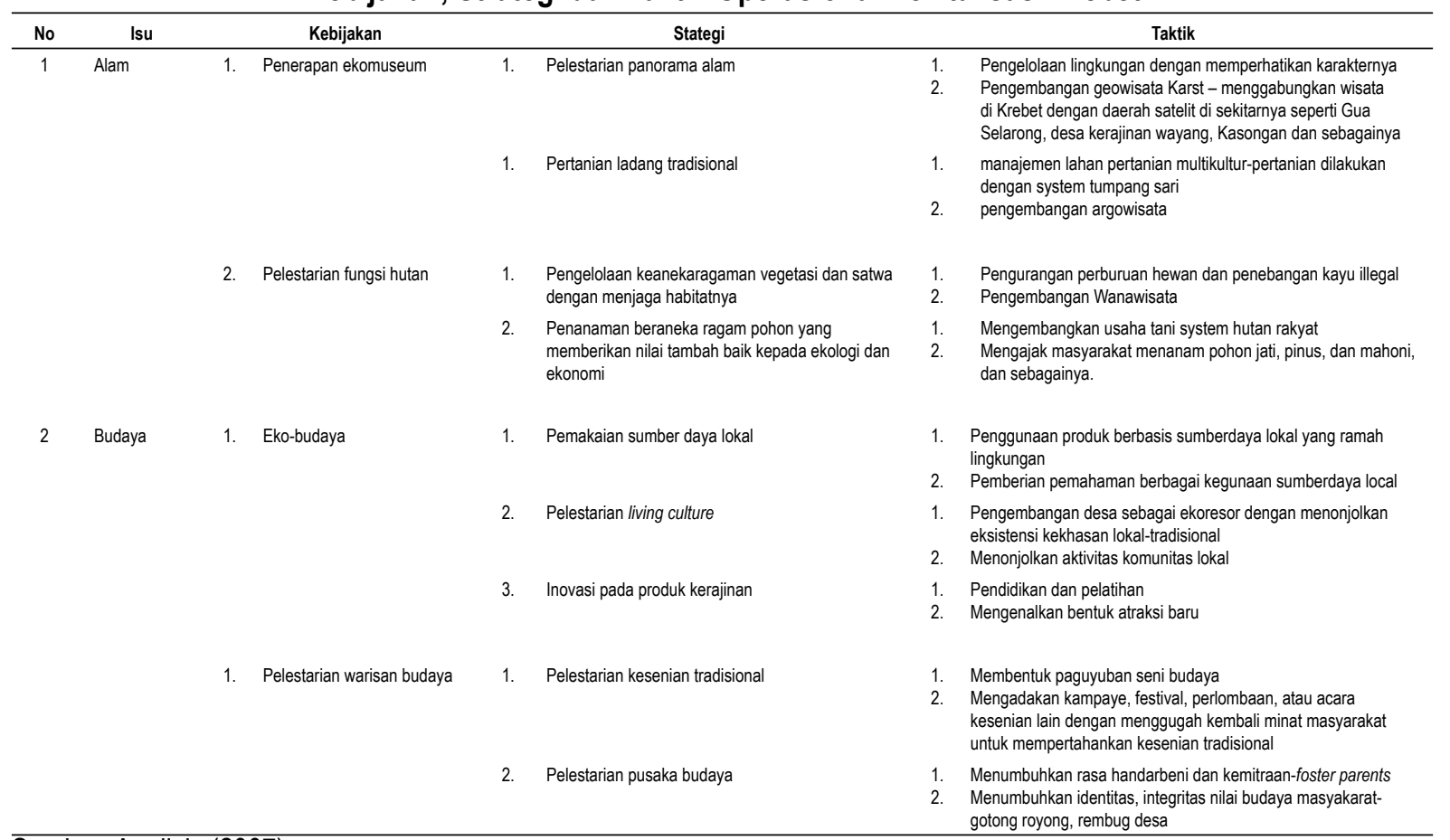

Sumber: Analisis (2007)

Berdasarkan Tabel 4 dengan menggunakan teknik AHP (penggaliannya menggunakan metode Delphi dengan mengeksplorasi pendapat 15 orang pakar yang dikumpulkan dalam dua putaran) diperoleh prioritas program revitalisasi yaitu penerapan kebijakan pelestarian warisan budaya dengan strategi pelestarian kesenian tradisional dan fokus operasionalnya adalah menumbuhkan perasaan memiliki (handarbeni) masyarakat terhadap saujana budaya (cultural landscape) Kawasan Krebet merupakan hal yang paling utama (18\%). Hal ini sekaligus dikombinasikan dengan adanya upaya kemitraan dengan pihak ketiga yang bersedia menjadi orang tua asuh (foster parents) misalnya dari BUMN bagi industri yang ada di wilayah tersebut.

Kemudian setelah itu perlu kebijakan ekobudaya dengan strategi inovasi pada produk kerajinan, penekanannya adalah pemberian pendidikan dan latihan kepada para pengrajin (bobot 15\%). Hal ini diikuti secara bersamaan dengan menumbuhkan identitas, integritas nilai budaya masyarakat seperti mempertahankan sifat gotong-royong dan rembug desa, sekaligus mengadakan kampanye, festival, perlombaan, atau acara kesenian lain dengan menggugah kembali minat masyarakat mempertahankan kesenian tradisional yang dimilikinya (masing-masing berbobot 6,3\%). Setelah itu kebijakan yang sebaiknya diambil adalah menerapkan kebijakan eko-budaya dengan strategi inovasi pada produk kerajinan, bentuknya adalah melakukan pengenalan atraksi dan 
amenitas yang selalu baru (5\%) tetapi tidak dengan menjiplak karya intelektual orang lain. Ekobudaya di sini, memiliki dasar pengertian melindungi kelestarian sistem ekologi dan sosial-budaya untuk kepentingan ekonomi yang diperuntukkan bukan hanya bagi generasi sekarang tetapi juga sebagai tanggung-jawab bagi kelangsungan kehidupan di masa datang.

Kebijakan berikut adalah menerapkan kebijakan ekobudaya dengan strategi mempertahankan living culture masyarakat setempat. Adapun operasionalnya adalah pengembangan kawasan perdesaan menjadi ekoresor bagi wisatawan dengan menonjolkan eksistensi kekhasan lokal-tradisional yang dimilikinya (4,4\%). Prioritas berikutnya adalah menetapkan lahan Kawasan Krebet menjadi wilayah ekomuseum, strateginya adalah pelestarian panorama alam dengan menekankan pada pengelolaan lingkungan dengan memperhatikan karakternya sekaligus mengembangkannya dengan menadakan geowisata "Karst" karena akan menarik banyak peneliti geolog dan penerapan strategi pertanian yang berafiliasi dengan kearifan lokal, tidak menggunakan pupuk anorganik dan mengingat lahan bersifat tadah hujan maka taktik operasionalnya adalah melakukan manajemen lahan pertanian secara multikultur, pertanian dilakukan dengan sistem tumpang sari tidak hanya satu jenis species saja. Hal ini untuk meningkatkan efektivitas dan efisensi lahan dengan memanfaatkan keberadaan air hujan yang relatif pendek sebagai sumber penghidupannya (masing-masing berbobot $4,2 \%$ ).

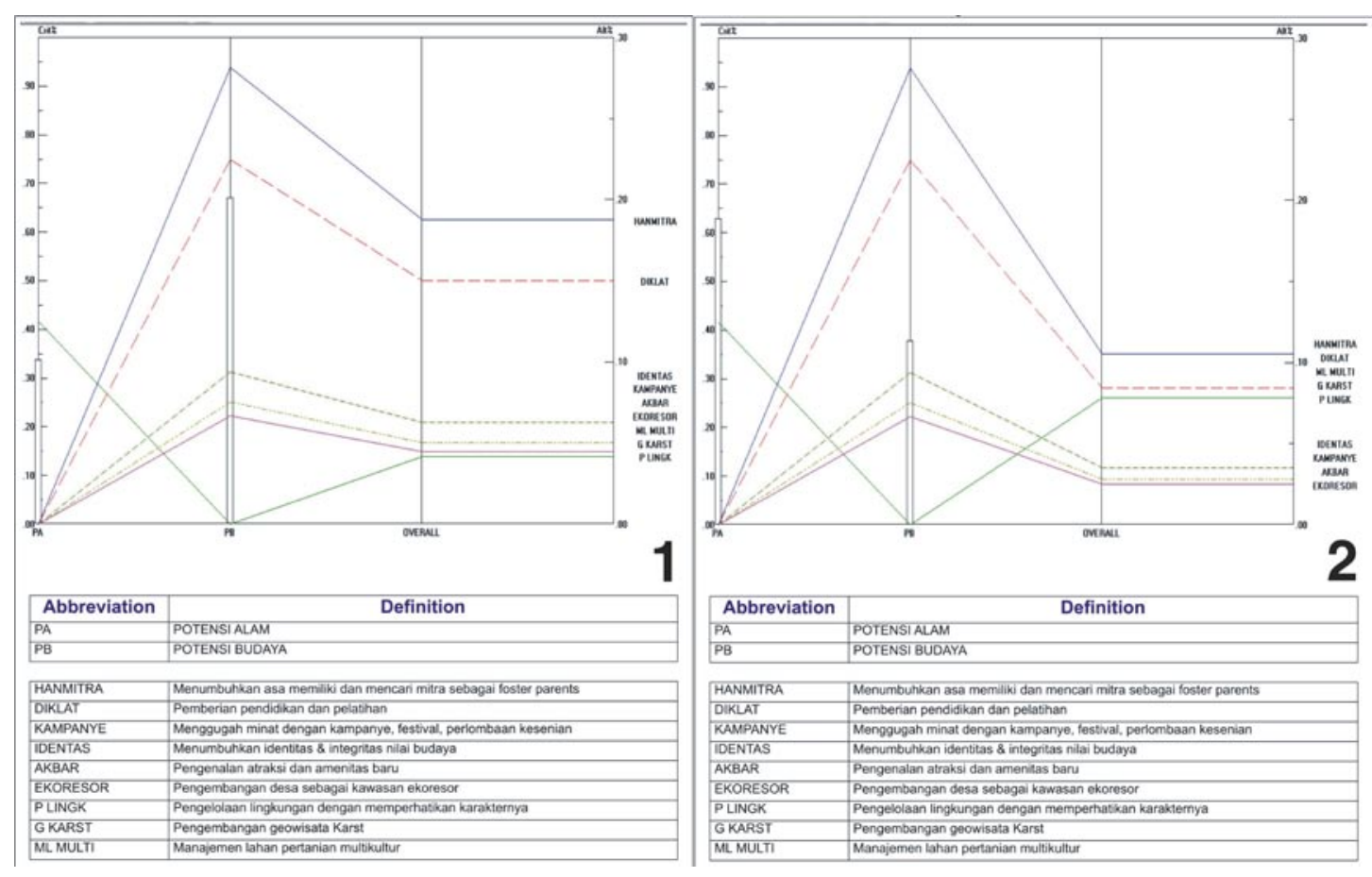

Sumber: Hasil Pengolahan Data (2007)

\section{Gambar 6}

Analisis Sensitivitas Dengan PHA

Analisis dari proses AHP pada Gambar 6-1 memperlihatkan bahwa pada kondisi normal kebijakan terhadap potensi kebudayaan dengan fokus pada taktik HANMITRA (menumbuhkan rasa memiliki atau handarbeni dan kemitraan dengan orang tua asuh) dan DIKLAT (memberikan pendidikan dan latihan kepada para pengrajin) terlihat pada urutan pertama dan kedua. Jika dilakukan perubahan, misalnya memprioritaskan unsur pengelolaan potensi alam di atas kepentingan potensi kebudayaan sampai dengan 60 persen pun, tampak bahwa HANMITRA dan DIKLAT masih menempati kedudukan nomor satu dan dua (Gambar 6-2). Hal ini menunjukkan prioritas kebijakan 
untuk melestarikan warisan budaya yang dimiliki masyarakat Krebet dan selalu menampilkan inovasi terhadap produk yang dihasilkan menjadi sesuatu yang hakiki di dalam program revitalisasi.

Analisis sensitivitas dalam memilih prioritas program revitalisasi Kawasan Krebet memiliki rasio ketidak konsistenan yang menunjukkan angka 0,00 sehingga diyakini bahwa derajad kesalahan (error) dalam pengambilan keputusan memiliki probabilitas di bawah 1 persen (Gambar 7).

\section{Memilih Pioritas Program Revitalisasi Kawasan KREBET}

Compare the relative IMPORTANCE with respect to: GOAL

Node: 0

1=EQUAL 3=MODERATE
\begin{tabular}{|l|l|l|l|l|l|l|l|l|l|l|l|l|l|l|l|l|l|l|l|}
\hline 1 & PA & $9=$ =STRONG & 7=VERY STRONG & $9=$ =EXTREME & PB \\
\hline
\end{tabular}

\begin{tabular}{|l|l|}
\hline \multicolumn{1}{|c|}{ Abbreviation } & \multicolumn{1}{c|}{ Definition } \\
\hline Goal & Memilih Pioritas Program Revitalisasi Kawasan KREBET \\
\hline PA & POTENSI ALAM \\
\hline PB & POTENSI BUDAYA \\
\hline
\end{tabular}

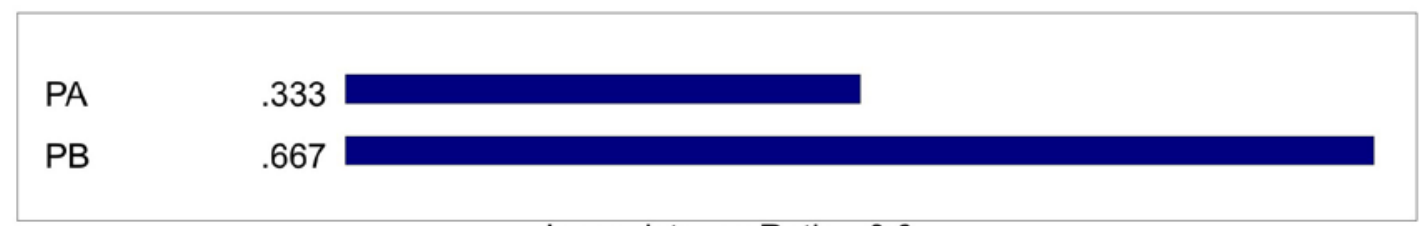

Inconsistency Ratio $=0.0$

Sumber: Hasil Pengolahan Data (2007)

Gambar 7

Rasio Ketidak-konsistenan

\section{PENUTUP}

Revitalisasi potensi saujana budaya (gabungan modal alam dan kebudayaan) yang dimiliki Kawasan perdesaan Krebet perlu menggunakan pendekatan eko-ekonomi, artinya pada saat ekonomi menjadi aras pembangunan, maka kearifan lokal sosial-budaya masyarakat dan fungsi ekologi alam menjadi pengontrol dan penyeimbang stabilitas untuk menjaga poduktivitas lingkungan agar tetap lestari. Hal ini mengingatkan bahwa pertumbuhan ekonomi saja (misalnya dengan target PAD setinggi-tingginya) dapat meningkatkan kuantitas tetapi tidak dapat lestari bahkan eksploitasi besar-besaran justru akan menimbulkan masalah lain yaitu degradasi lingkungan. Karena itu harus disadari, pertumbuhan berkelanjutan tidak mungkin tetapi pembangunan ekonomi, misalnya melalui pariwisata budaya, dapat dicapai jika keseimbangan fungsi ekologi dipertahankan sesuai dengan karakter sosial-budaya masyarakat lokal yaitu cara mereka hidup, bekerja dan berkarya. Dengan perkataan lain, pemanfaatan budaya dan alam yang dijadikan sebagai sumberdaya atraksi pariwisata harus dilakukan dengan caracara yang eko-ekonomi dan memperhatikan kearifan lokal sosial-budaya masyarakat. Kebudayaan merupakan sebuah agen perubahan, alam adalah medium sedangkan hasilnya adalah warisan budaya (cultural heritage).

Oleh karena itu, pemuasan kebutuhan pada saat ini harus memperhatikan kebutuhan generasi mendatang dengan memanfaatkan kearifan pengetahuan tradisionalnya dalam penggunaan bahan baku lokal dan dilandasi kesadaran bahwa manusia bagian integral (menyatu) tidak terpisahkan dari alam; manusia tidak dapat memanipulasi alam lepas dari keseluruhan dinamika organisme yang ada di dalamnya sehingga perlu relasi sinergi-sistemik.

Implikasinya, untuk mendukung revitalisasi Kawasan perdesaan Krebet maka kebijakan, strategi dan taktik 
yang harus dijalankan pihak otoritas bersama masyarakat adalah mengelola amenitas yang diberikan alam dengan memperhatikan daya dukung lingkungan, sehingga pemanfaatannya sesuai degan asas efisiensi hasil ekonomi yang memperhatikan ekologi sekaligus budaya masyarakat. Di samping itu tidak boleh dilupakan pula faktor edukasi karena pemahaman terhadap perlunya melestarikan fungsi ekologi bagi kepentingan ekonomi, dan juga keahlian mengelola bisnis dan mempertajam ketrampilan untuk menciptakan kreasi produk baru dasarnya adalah pengetahuan. Oleh karena itu sosial-budaya masyarakat dalam bentuk kekhasan adat, ritual dan spiritual kehidupan masyarakat akan lestari jika dapat menghasilkan nilai ekonomi dengan memanfaatkan sistem ekologi alam secara efisien dan efektif dilandasi pengetahuan yang cukup. Penggunaan sumberdaya yang bersifat kuantitas bertujuan pencapaian hasil jangka pendek perlu diubah menjadi fokus kualitas, ekologi, orientasi manusia sebagai tujuan akhir pembangunan, perspektif hasil jangka panjang dan keadilan sosial antar generasi.

\section{DAFTAR PUSTAKA}

Australia ICOMOS. (1995), Asia-Pacific Regional Workshop on Associative Cultural Landscapes: A Report by Australia ICOMOS to the World Heritage Committee. 27-29 April, Australia ICOMOS, New South Wales.

Australian National University (ANU)., (2000), Challenges for Heritage Conservation and Sustainable Development in the $21^{\text {st }}$ century. July 4. Proceedings Heritage Economics. Australian National University Canberra, Australia.

Ayala, H., (1996), Resort ecoturism: A Paradigm for the $21^{\text {st }}$ Century. Cornell Hotel and Restaurant Administration Quarterly, Vol 37, No. 5, pp 46-53.

Brown, L.R., (2001), Eco-Economy: Building an Economy for the Earth. New York: W.W. Norton \& Company.

Coleman, V. 2002. Cultural Landcapes Charette Background Paper. Presented at NSW Heritage Office. http://www. austlii.edu.au.

Costanza, R., (1997), The Value of the World's Ecosystem Services a Natural Capital. Nature, 387-395.

Erasmus University Rotterdam (EUR), (2003), A Handbook of Cultural Economics. Rotterdam, Netherlands: Digital Academic Repository-Erasmus University Rotterdam.

Getty Conservation Institute (GCI). (1998), Economics and Heritage Conservation: A Meeting Organized by the Getty Conservation Institute. Los Angeles: Getty Center.

Goeldner, C.R. and J.R.B. Ritchie., (2003), Tourism: Principles, Practices, Philosophies. (9 $9^{\text {th }}$ ed.). New York: John Wiley \& Sons.

Hair, J.F., Jr., W.C. Black, B.J. Babin, R.E. Anderson., and R.L. Tatham., (2006), Multivariate Data Analysis. (5 ${ }^{\text {thed.). }}$ Upper Saddle River, NJ, USA: Pearson Education, Inc.

Jaringan Pelestarian Pusaka Indonesia (JPPI), International Council on Monuments and Sites (ICOMOS) Indonesia dan Kementrian Kebudayaan dan Pariwisata R.I., (2003), Piagam Pelestarian Pusaka Indonesia. Ciloto: Jaringan Pelestarian Pusaka Indonesia, International Council on Monuments and Sites (ICOMOS) Indonesia dan Kementrian Kebudayaan dan Pariwisata R.I.

Langabeer II, J. (1998), Competitive Strategy in Turbulent Healthcare Markets: An Analysis of Financially Effective Teaching Hospitals. Journal of Healthcare Management, Vol. 43, No. 6, pp 512-526.

Merric, H.J. and J. Hunt., (1998), Ecotourist' motivational and demographic characteristics: A case of North Carolina travelers. Journal of Travel Research, Vol 36 (Spring), pp 57-61. 
Moons, E. (2003), The Development and Application of Economic Valuation Techniques and Their Use in Environmental Policy: A survey. Belgium: Energy, Transport and Environment, Center for Economic Studies, Katholieke Universiteit Leuven.

Nagel, S.S. (1982), Policy Evaluation: Making Optimum Decisions. New York, USA: Praeger Publisher.

Ohara, K. (1998), The Image of 'Ecomuseum' in Japan. Pacific Friends, Vol 25, No. 12, pp. 26-27.

Palumbo, D.J. (1977), Statistics in Political and Behavioral Science. (Rev Ed). NY, USA: Colombia University Press.

Santosa, S. (2000), Buku Latihan SPSS Statistik Multivariat. Jakarta: PT. Gramedia Pustaka Utama.

Sirakaya, E. and R.W. McLellan. (1998), Modelling Tour Operators' Voluntary Compliance with Ecotourism Principles: a Behavioral Approach. Journal of Travel Research, Vol. 36 (winter), pp. 42-55.

Smith, V. (1977), Host and Guest. Chicago, Philadelphia, USA: University of Pensylvania Press.

Throsby, D. (1999), Cultural Capital. Journal of Cultural Economics, Vol. 23, pp. 3-12. . (2001), Economics and Culture. Cambridge, UK: Cambridge University Press.

Undang-undang RI Nomor 23 tahun 1997 tentang Pengelolaan Lingkungan Hidup.

Von Droste, B., H. Plachter., and M. Rössler. (1995), Cultural Landscapes of Universal Value. New York: Gustav Fischer Verlag in Colaboration with UNESCO.

Watson, C.J., P. Ballingsley., D.J Croft., and D.V. Hundsberger. (1993), Statistic for Management and Economics. Englewood Cliffs, NJ, USA: Prentice Hall, Inc.

Wight, P. (1993), Ecotourism: Ethics or Eco-sell? Journal of Travel Research, 31 (winter): 3-9.

Yogyayes. Com. (2007), Wayang Batik Course. www.yogyayes.com.

Zikmund, W.G. (1991), Exploring Marketing Research. Chicago, USA: Dryden Press. 